\title{
ADAPTATION OF EXISTING BREAKWATERS TO SEA LEVEL RISE - OVERTOPPING EFFECT
}

\author{
Dang Trinh NGUYEN, Jérôme BROSSARD
}

\author{
Laboratoire Ondes et Milieux Complexes, UMR 6294, CNRS-Université du Havre, 53 \\ rue de Prony, BP 540, 76058 Le Havre Cedex, France.
}

\begin{abstract}
This paper describes the wave overtopping measurements of small scale maritime breakwater in sea level rise scenarios which are supposed in French program GICC (Gestion et Impacts du Changement Climatique - Management and Impacts of Climate Change). Many reinforced solutions have been carried out with the purpose to conserve the overtopping rate; among them, the influence of raising freeboard crest is analyzed. The test results are compared with results from literature and with the empirical models presented by Owen (1980), Van der Meer (1998) and Besley (1999). Since then, a guideline is proposed for a better prediction of wave overtopping with various types of high crown-wall.
\end{abstract}

Keywords: Maritime breakwater-Overtopping rate-Reinforced structure-Structure's crown-wall.

\section{INTRODUCTION}

One of the expected consequences of climate change is the sea level and ocean rise. This variation of the mean sea level and the effects induced by the increase of wave heights in front of structure leading to increasing of wave overtopping behind the protected marine breakwater, and thus to flood hazards as well as uncertainties in exploitation of sheltered areas not included in the specifications of the original design. To preserve the human activities in the coastal areas or/and harbor facilities, the strength of the existing coastal protections have to be reinforced in particular from the point of view of the flood caused by overtopping. This question has been the objective point of the national program GICC-SAO POLO (a program managed by the Ministry of Ecology, Sustainable Development, Transportation and Housing) in 2010 and 2011.

The "Laboratoire Ondes et Milieux Complexes" of University of le Havre had to study experimentally reinforcement solutions for maritime breakwater. Three water level scenarios were examined: a reference scenario with a water height $\mathrm{h}=7 \mathrm{~m}$ at toe of the structure, a "normal" scenario with a water level elevation to $0.5 \mathrm{~m}(\mathrm{~h}=7.5 \mathrm{~m})$ and a "extreme" scenario with raising the water level to $1 \mathrm{~m}(\mathrm{~h}=8 \mathrm{~m})$.

In this respect, the crest elevation of a coastal structure is an important design parameter as it is directly related to the amount of wave overtopping. Reinforcement design of the crest elevation of a seawall, usually vertical crown wall and recurved crown wall are applied because of their easy construction and immediate solution for engineering. Therefore, the tests are carried out with these two crest configurations for limiting the volume of overtopping in the elevation of mean water level which is modeled in small scaled wave flume.

\section{WAVE OVERTOPPING IN INITIAL CONDITION}

For studying the effect of overtopped wave in moderate sea level, it has been chosen a breakwater with Antifer armour type. The geometry and material choice are determined, for armour's stability, by formula Van der Meer (1998) and, for wave overtopping discharge, by formula TAW (2002) with arbitrary bathymetry, wave condition and mean water level. The $2 \mathrm{D}$ experimental investigations at small-scale was all performed in a wave flume of $26 \mathrm{~m}$ long, $0.88 \mathrm{~m}$ wide, and $1.2 \mathrm{~m}$ height at University of Le Havre (France). 


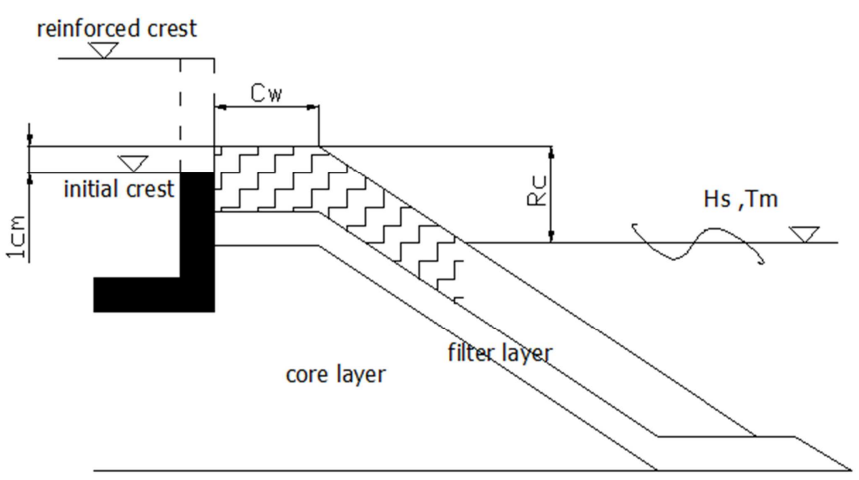

Fig. 1. Cross section of model Antifer breakwater.

The initial conditions are:

- band of offshore wave period: $7 \mathrm{~s} \leq \mathrm{T}_{\mathrm{m}} \leq 11 \mathrm{~s}$

- range of offshore significant wave height: $5 \mathrm{~m} \leq \mathrm{H}_{\mathrm{s} 0} \leq 10 \mathrm{~m}$

- $\quad$ seabed slope in front of structure: $2 \%$

- water depth at toe structure: $\mathrm{h}=7 \mathrm{~m}$

- $\quad$ acceptable overtopping discharge: $\mathrm{q}=50 \mathrm{l} / \mathrm{s} / \mathrm{m}$

- armour layer: artificial block in Antifer type

\section{Experimental condition}

The wave flume's dimensions and tested wave conditions lead us to choose the scale of 30.5 . The seabed slope is $2 \%$. The "non-infinite" water depth condition in wave paddle is considered for reproducing the wave in deep water. All of results in this paper are presented in deep water wave conditions because of the assumption that there is no influence of raising sea level on wave condition in offshore climate.

The table 1 shows the tested wave conditions with the initial water depth at the toe of structure $\mathrm{h}=7 \mathrm{~m}$ in prototype scale.

Table 1: Significant wave height and mean wave period at the finite depth used in all tests.

\begin{tabular}{|c|c|c|c|c|}
\hline & $\mathbf{T}_{\mathbf{m}}=\mathbf{7} \mathbf{~}$ & $\mathbf{T}_{\mathbf{m}}=\mathbf{8 ~ \mathbf { ~ }}$ & $\mathbf{T}_{\mathbf{m}}=\mathbf{9 . 4} \mathbf{~}$ & $\mathbf{T}_{\mathbf{m}}=\mathbf{1 0 . 4} \mathbf{~}$ \\
\hline $\mathrm{h}=7 \mathrm{~m}$ & $\mathrm{H}_{\mathrm{s} 0}=4.5 ; 5.7 ; 6.5 ; 6.9$ & $\mathrm{H}_{\mathrm{s} 0}=4.9 ; 5.7 ; 6.8 ; 7.5 ; 7.8 ; 8.1$ & $\mathrm{H}_{\mathrm{s} 0}=5 ; 6.2 ; 7.3 ; 8.4$ & $\mathrm{H}_{\mathrm{s} 0}=4.7 ; 5.8 ; 7.3$ \\
\hline
\end{tabular}
3.3 is used.

For an offshore sea state in prototype, a JONSWAP spectrum with a peak-enhancement factor of

Antifer blocks have been chosen as armour layer of breakwater. In practical design, the optimal placement method need to adapt to both of two conditions: ensuring the armour stability (including less movement of the second layer and sliding of the first layer) and limiting the overtopping wave due to layer's porosity.

The placement technique was made from the Frens (2007)'s work. The author assesses the impact of 17 different placement methods, with different packing densities, on the stability of Antiferblock armour layers. These placement methods are divided into regular, irregular and alternative placement methods.

Based on researches above, the alternative placement technique has been chosen with first layer in regular placement for avoiding the sliding down of the whole armour just in the beginning moment of test, and second layer with irregular placement technique with high porosity as possible. The geometry of the Antifer block is presented in Figure 2 and Table 2.
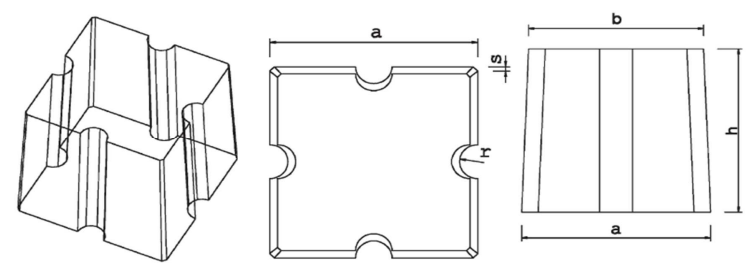

Fig. 2. The oblique, plan view and cross-section of the Antifer block. 


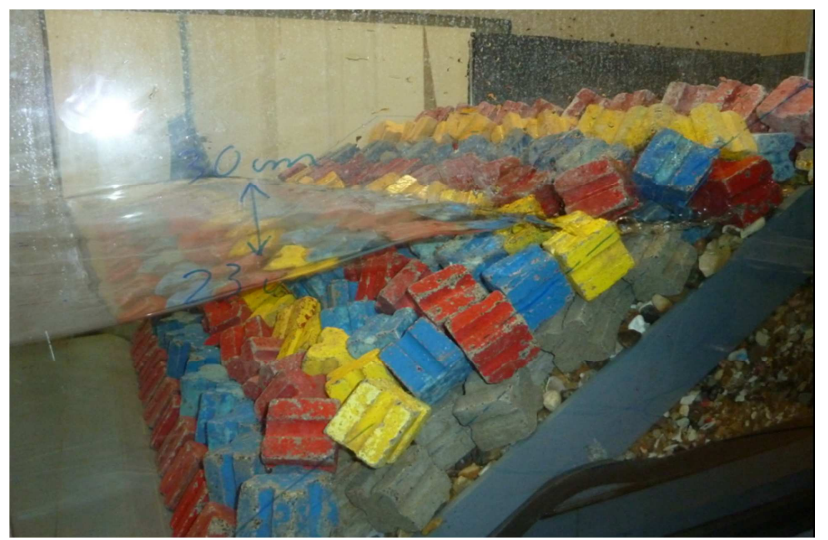

Fig. 3. Image of model Antifer breakwater after installation.

Table 2. The characteristics of the model Antifer cube blocks.

\begin{tabular}{|l|c|c|c|c|c|c|c|c|}
\hline & $\mathbf{a}(\mathbf{c m})$ & $\mathbf{b}(\mathbf{c m})$ & $\mathbf{h}(\mathbf{c m})$ & $\mathbf{r}(\mathbf{c m})$ & $\mathbf{s}(\mathbf{c m})$ & $\mathbf{m}(\mathbf{g})$ & $\mathbf{V}\left(\mathbf{c m}^{\mathbf{3}}\right)$ & $\boldsymbol{\rho}_{\mathbf{s}}\left(\mathbf{k g} / \mathbf{m}^{\mathbf{3}}\right)$ \\
\hline Antifer & 5.4 & 5.1 & 5.4 & 0.75 & 0.15 & 314 & 128 & 2450 \\
\hline
\end{tabular}

Table 3. The block number, porosity values and packing density values.

\begin{tabular}{|l|c|}
\hline Total number of block $\mathrm{N}_{\mathrm{BL}}$ & 274 \\
\hline Packing density, $\Psi_{\mathrm{s}}$ & $57 \%$ \\
\hline Layer thickness, $\mathrm{t}$ & $12.5 \mathrm{~cm}$ \\
\hline Layer thickness coefficient, $\mathrm{k}_{\Delta}$ & 1.24 \\
\hline Real porosity, $\mathrm{P}_{\mathrm{r}}$ & $54 \%$ \\
\hline
\end{tabular}

The overtopping discharges were measured on whole width of wave flume equal to $0.88 \mathrm{~m}$ by a tank with cylindrical collector tube associated with an electric pump and a flow meter (Figure 4). The overtopping water was continuously re-injected at the seaside. This system is capable of measuring and draining 800 litters maximum in 1956 seconds of test duration that corresponds to 3 hours storm period in situ.

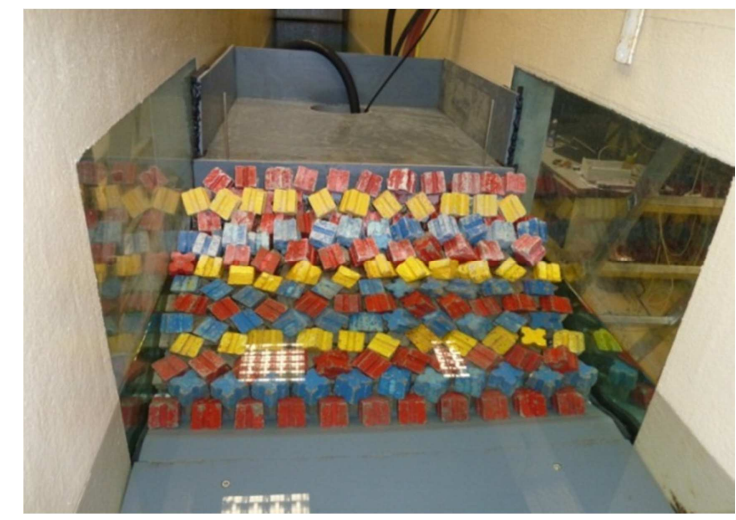

Fig. 4. Breakwater model with system measuring overtopping volume

\section{Predicted models}

In this section, the results are compared between the obtained values in present tests with predictions deduced from semi-empiric formulae Owen (1980), Van der Meer et al. (1998) and Besley (1999). 
The formulae presented by Owen (1980) and Van der Meer et al. (1998) are well known and widely used. These formulas originally are based on extensive data sets from model tests with smooth impermeable sloping structures. By applying a reduction factor for the slope roughness, the formulas are applicable to rock slopes.

\section{Owen - Besley formula}

The wave-overtopping formula by Owen (1980) reads:

$$
q / g H_{s} T_{m}=a_{0} \cdot \exp \left(-b_{0} \frac{R_{c}}{T_{m} \sqrt{g H_{s}}} \frac{1}{\gamma_{r}}\right)
$$

With validity range $0.05<\frac{R_{c}}{T_{m} \sqrt{g H_{s}}}<0.3$, in which, $\mathrm{H}_{\mathrm{s}}=\mathrm{H}_{\mathrm{m} 0}$ is significant incident wave height at toe of structure, $\gamma_{\mathrm{r}}$ (note that $\gamma_{\mathrm{f}}$ has the same meaning in Van der Meer et al. (1998) formula) is a surface roughness reduction factor which takes into account the combined effect on slope roughness and permeability, $\mathrm{a}_{0}, \mathrm{~b}_{0}$ are empirically derived dimensionless coefficients whose values depend on the breakwater slope, thus for $1: 1.5$ seawall slope the value $a_{0}=8.84 .10^{-3}$ and $b_{0}=19.9$ are considered.

To take account of a permeable crest, Besley (1999) suggests multiplying the predicted overtopping rate from the Owen formula with a reduction factor:

$$
C_{r}=3.06 \exp \left(-1.5 \frac{C_{w}}{H_{s}}\right)
$$

Valid for $\mathrm{C}_{\mathrm{w}} / \mathrm{H}_{\mathrm{s}}>0.75$ where $\mathrm{C}_{\mathrm{w}}$ is the crest berm width, if $\mathrm{C}_{\mathrm{w}} / \mathrm{H}_{\mathrm{s}}<0.75$ the reduction of wave overtopping is negligible $\left(\mathrm{C}_{\mathrm{r}}=1\right)$.

Hence, an Owen - Besley combination formula can be expressed by:

$$
q / g H_{s} T_{m}=C_{r} \cdot a_{0} \cdot \exp \left(-b_{0} \frac{R_{c}}{T_{m} \sqrt{g H_{s}}} \frac{1}{\gamma_{r}}\right)
$$

The Figure 5 compares the measured on predicted dimensionless overtopping $Q^{*}=\frac{q}{g H_{m 0} T_{m}}$ in relation to the dimensionless crest freeboard $R^{*}=\frac{R_{c}}{H_{m 0}}\left(\frac{s_{0 m}}{2 \pi}\right)^{0,5}$ with $s_{0 m}=\frac{2 \pi H_{m 0}}{g T_{m}^{2}}$. The best fitting is obtained for roughness factor value $\gamma_{\mathrm{r}}=0.4$.

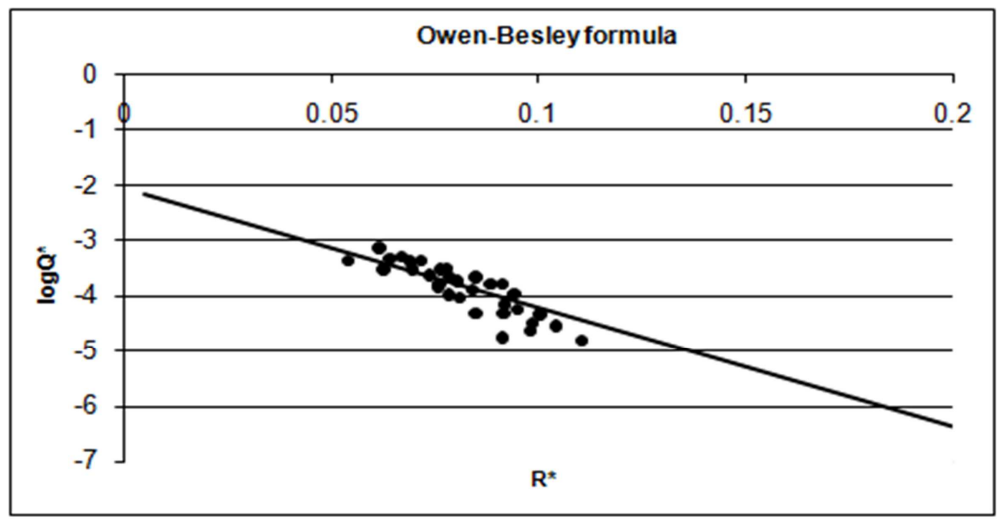

Fig. 5. Measured and predicted comparison in Owen formula with crest berm reduction factor as proposed by Besley in small scale tests.

\section{Van der Meer - Besley formula}

The wave-overtopping formula presented in Van der Meer et al. (1998) and TAW (2002) is: 


$$
\begin{gathered}
q / \sqrt{g H_{m 0}^{3}}=\frac{0,067}{\sqrt{\tan \alpha}} \xi_{m-1,0} \gamma_{b} \exp \left(-4,75 \frac{R_{c}}{H_{m 0}} \frac{1}{\xi_{m-1,0} \gamma_{b} \gamma_{v} \gamma_{f} \gamma_{\beta}}\right) \\
\text { With a maximum of: } q / \sqrt{g H_{m 0}^{3}}=0.2 \exp \left(-2,6 \frac{R_{c}}{H_{m 0}} \frac{1}{\gamma_{f} \gamma_{\beta}}\right) \\
\text { and breaker parameter } \xi_{m-1,0}=\frac{\tan \alpha}{\sqrt{\frac{2 \pi H_{m 0}}{g T_{m-1,0}^{2}}}}
\end{gathered}
$$

$H_{s}$ is significant wave incident height at toe of structure. Reduction factors $\gamma_{b}, \gamma_{\mathrm{f}}, \gamma_{\beta}, \gamma_{\mathrm{v}}$ include effects of a berm, surface roughness, oblique wave attack and a vertical wall on top of the slope, respectively. It is noted that $\gamma_{\mathrm{v}}=1$ for the case of non-vertical wall on top of the slope.

In adding the Besley (1999) roughness berm reduction factors, the Van der Meer - Besley formula can be expressed by:

$$
\begin{aligned}
& q / \sqrt{g H_{m 0}^{3}}=C_{r} \cdot \frac{0,067}{\sqrt{\tan \alpha}} \xi_{m-1,0} \gamma_{b} \exp \left(-4,75 \frac{R_{c}}{H_{m 0}} \frac{1}{\xi_{m-1,0} \gamma_{b} \gamma_{v} \gamma_{f} \gamma_{\beta}}\right) \\
& \text { Where: } C_{r}=3.06 \exp \left(-1.5 \frac{C_{w}}{H_{s}}\right)
\end{aligned}
$$

In both formulas, Owen and Van der Meer have proposed a value of surface roughness reduction factors in the range $\gamma_{\mathrm{r}}=0.5-0.55$ for the case of rough rock slope.

When Eq.(7) formula is used for comparison with our laboratory experiment, the calculated overtopping rate is more important than measured as seen in figure 6 for $\gamma_{\mathrm{f}}=0.4$ (the same value of Owen - Besley's model). This problem is left for further discussion with another model test with the same conditions of offshore wave and type of work.

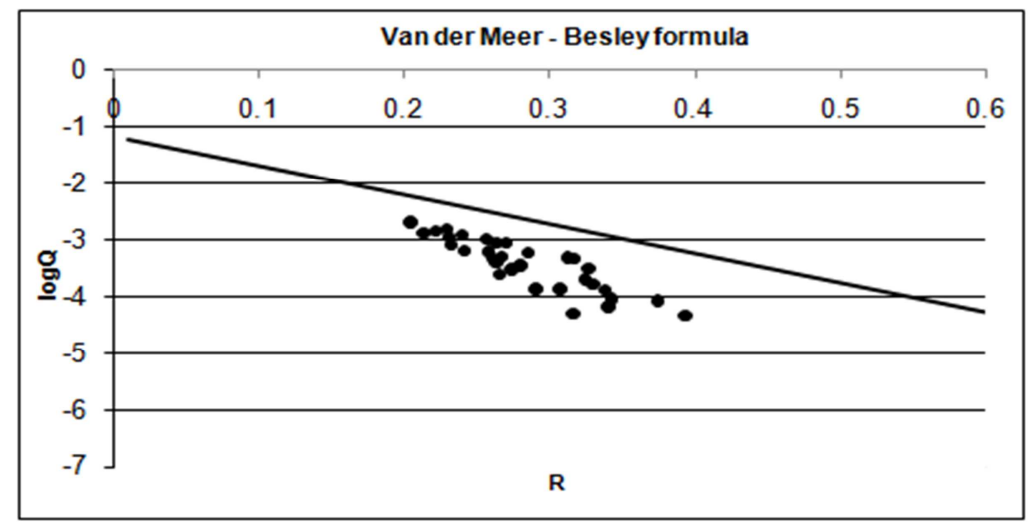

Fig. 6. Measured and predicted comparison in Van der Meer formula with crest berm reduction factor as proposed by Besley in small scale flume $\left(\boldsymbol{\gamma}_{\mathbf{f}}=\mathbf{0 . 4}, Q=\frac{q}{\sqrt{g H_{m 0}^{3}}}, R=\frac{R_{c}}{H_{m 0} \xi_{m-1,0}}\right)$

\section{Verification by the measurement in situ breakwater}

Actually, there are many researches in purpose to determinate the adequate roughness factor $\gamma_{\mathrm{f}}$ ( or $\gamma_{\mathrm{r}}$ ) used for model semi-empiric. The breakwaters Antifer types are studied in different scales; however the result is still contradictory. The scale effect among many model tests seems to be one of these main reasons. Therefore, Troch et al., 2004 carried out their field measurements of wave overtopping over an Antifer armour breakwater at Zeebrugge, Belgium during the period 1999-2003. Wave heights range between $\mathrm{H}_{\mathrm{s}}=2.6$ and $3.9 \mathrm{~m}$ at toe of structure for wave record in a typical storm duration of 1 hour to 2 hours and peak periods ranging between $T_{p}=7$ and $10 \mathrm{~s}$. 
In retaining the roughness values $\gamma_{\mathrm{f}}=0.5$ as proposed by many scientists, the previous authors find the correlation between measured and predicted value when both Owen - Besley and Van der Meer Besley formulae are used with this Antifer configuration.

Furthermore, to overcome the scale effect in laboratory measurement Lykke Andersen et al. (2011) have examined this effect by comparing overtopping discharges in small scale and large scale tests. They have proposed a coefficient of scale effect $\boldsymbol{\gamma}_{\mathrm{s}}$ to resolve the difficulties in accurate reproduction of prototype conditions for waves and structure in the wave flume when prototype conditions are not known in sufficient details. These model tests were designed to avoid as many model effects as possible. Investigating overtopping rate measure in three levels of scale model: prototype measurement at Zeebrugge and Ostia breakwater, large scale of 1:7 and small scale measurement of 1:40 carried out in Aalborg University, with four breakwater crest geometries: low crown wall, normal crown wall, high crown wall and vertical wall.

As seen in the Figure 5, with the least square method for Owen - Besley's model, it can be inferred that $\gamma_{\mathrm{r}}$ (small scale $)=0.4$. The guidelines of using the reduction factors of scale effect in paper of Lykke Andersen et al. (2011), in case of rubble mound breakwater with a low crown wall, and $\mathrm{s}_{0 \mathrm{p}}$ of wave condition from $0.01-0.03$ in this test, the value of $\gamma_{s}=0.82$ is chosen. Therefore, the value of surface roughness $\gamma_{\mathrm{r}}$ (in prototype) $=0.49$ is determined adequate with the data in prototype measurement at Zeebrugge. The value $\gamma_{\mathrm{r}}$ (or $\left.\gamma_{\mathrm{f}}\right)=0.5$ is proposed for the best agreement between the prediction by empirical formula and result in full scaled measurement in Zeebrugge's data. As regards the Van der Meer - Besley formula comparison, the overestimation in predicting wave overtopping in both small and large scale is required the lower value of $\gamma_{\mathrm{f}}$ used in future researches.

\section{SEA LEVEL RISE AND SOLUTIONS OF REINFORCEMENT}

The first idea to conserve the overtopping specification with an anticipated mean sea level is to increase the height of the crest wall. This solution of reinforcement is examined in this section for two scenarios of sea level raising $0.5 \mathrm{~m}$ and $1 \mathrm{~m}$.

\section{Depth water $h=7 \mathrm{~m}$ and rising sea height to $h=7.5 \mathrm{~m}$ :}

In first steps of changing sea climate scenario, an elevation of $0.5 \mathrm{~m}$ in sea level is assumed. In this experiment, the water depth at the toe of the breakwater increases from $\mathrm{h}=7 \mathrm{~m}$ to $\mathrm{h}=7.5 \mathrm{~m}$. The overtopping is measured with the method described in a previous section. In this experiment the raising of the crown wall's crest (Fig. 7) was obtained step by step with an increment of $1 \mathrm{~cm}$ in model scale $(0.3 \mathrm{~m}$ in prototype scale). When the measured overtopping discharge reached a level close of the initial one, the raising of the crown wall was stopped.

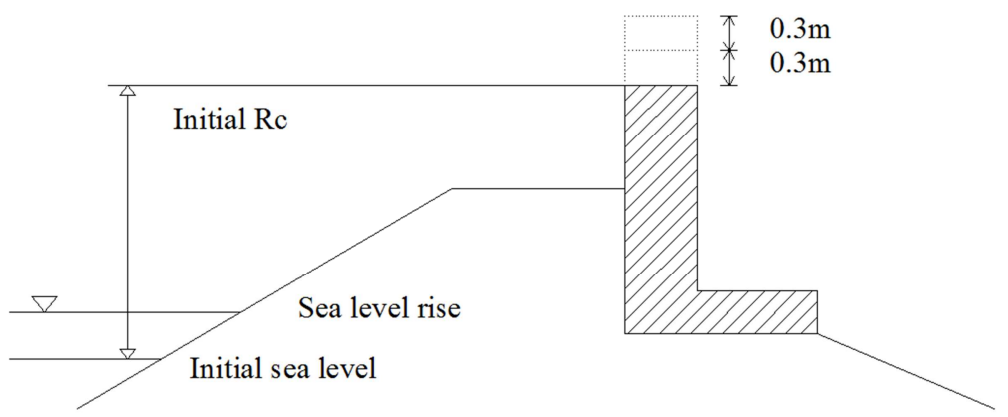

Fig. 7. Cross section of crown wall to adapting sea level rise.

In case of $0.5 \mathrm{~m}$ sea level rise, a raising crest wall of $1.5 \mathrm{~m}$ seems an optimal solution in these experiments. The Fig. 8 shows the results of overtopping discharge in initial conditions of sea level and of crown wall height; for $0.5 \mathrm{~m}$ sea level rise and initial crown wall height; for $0.5 \mathrm{~m}$ sea level rise and an increasing of the wall height of $1.5 \mathrm{~m}$. It can be noted that the chosen wall raising allows to conserve the initial overtopping discharge on the all range of wave period $\mathrm{T}_{\mathrm{m}}=[7 \mathrm{~s}-10.4 \mathrm{~s}]$ and on the all range for the tested wave height $\mathrm{H}_{\mathrm{s}}$. 
(a)

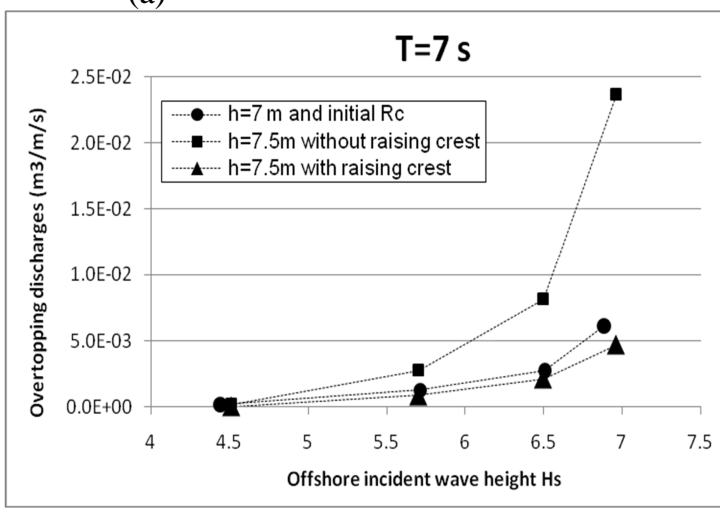

(c)

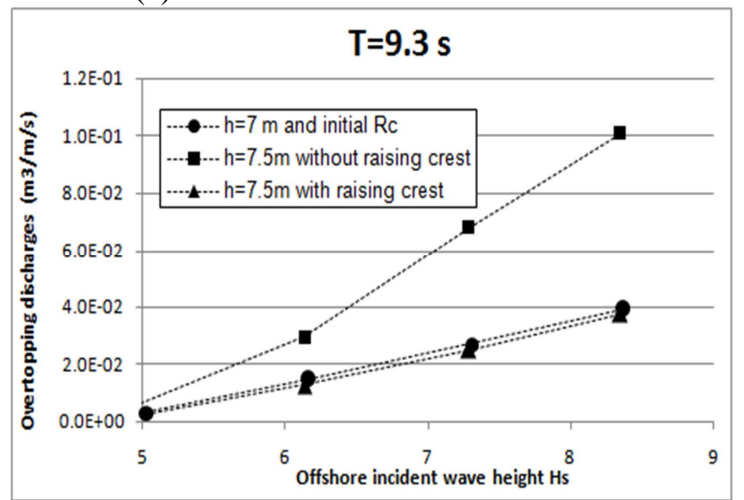

(b)

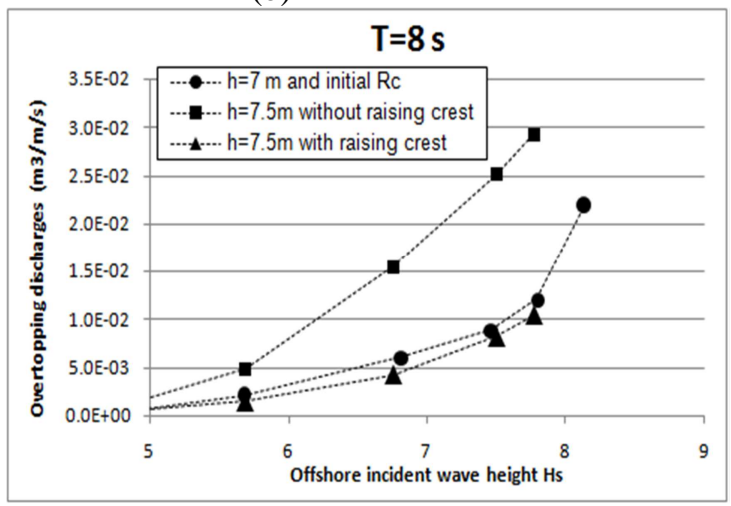

(d)

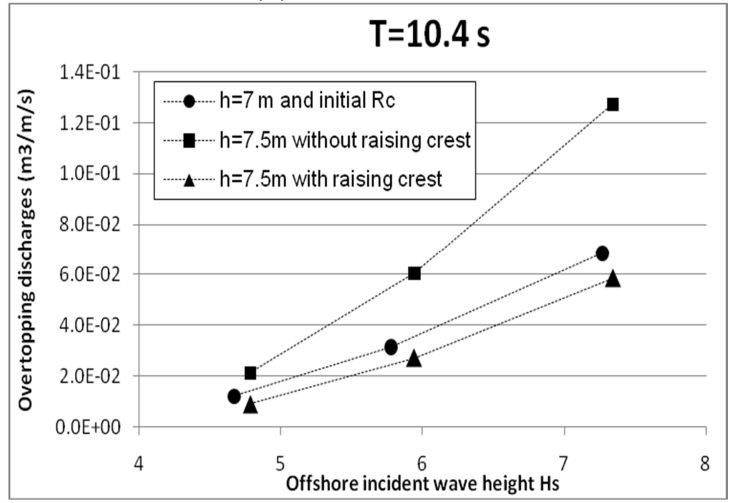

Fig. 8. Measured average overtopping rate before and after installing reinforced wall cases:

(a) $T_{m}=7 \mathrm{~s}$; (b) $T_{m}=8 \mathrm{~s} ;$ (c) $T_{m}=9.3 \mathrm{~s}$; (d) $T_{m}=10.4 \mathrm{~s}$.

\section{Depth water $h=7 \mathrm{~m}$ and rising sea height to $h=8 \mathrm{~m}$ :}

In this extreme condition of $1 \mathrm{~m}$ sea level rise, the overtopping discharge can become very large. Some tests carried out with only raising of the height of crown wall in the same manner of previous case led to a non-realistic wall. Thus, the using of a recurved wall has been chosen with a geometry presented in Fig. 9.

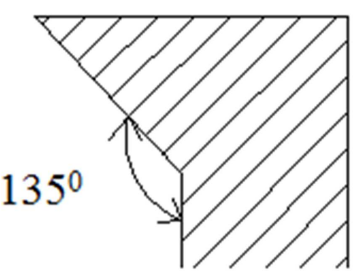

Fig. 9. Cross section of recurved crown wall

An interesting result observed in Fig. 10 is the recurved crown wall having more efficient in sustaining the wave overtopping for low wave period ( $7 \mathrm{~s}$ and $8 \mathrm{~s}$ ) than for long wave period $(9.3 \mathrm{~s}$ and $10.4 \mathrm{~s})$.

In circumstance of lower wave period $\left(\mathrm{T}_{\mathrm{m}}=7 \mathrm{~s}, 8 \mathrm{~s}\right)$, the tests are conducted for finding the optimal crest wall height. As seen in the test results in Fig. 10, for conserving the initial threshold value of mean overtopping discharge $\mathrm{q}$, the additional recurved wall height of $1.2 \mathrm{~m}$ will not be ensured the safety of structure with acceptable overtopping discharge which is defined in EurOtop (2007) for each level and type of structure. In the other hand, the additional recurved wall height of $1.8 \mathrm{~m}$ will reduce more overtopping volume than expected, thus this less economical solution is inconvenient for construction design. Finally, the use the $1.5 \mathrm{~m}$ (in prototype) recurved crown wall in these tests group of short waves seems to be rational. For long wave period group tests with $\mathrm{T}_{\mathrm{m}}=9.3 \mathrm{~s}$ and $10.4 \mathrm{~s}$, in the same manner of analyse, the $1.8 \mathrm{~m}$ in height of additional recurved wall will satisfy our expectation. 
(a)

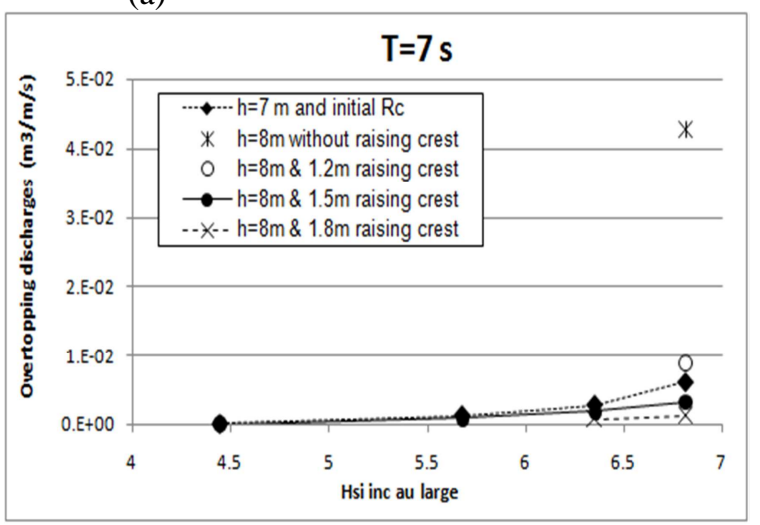

(c)

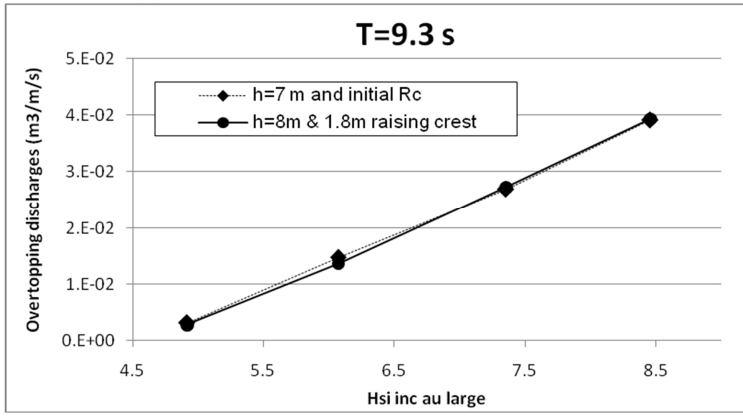

(b)

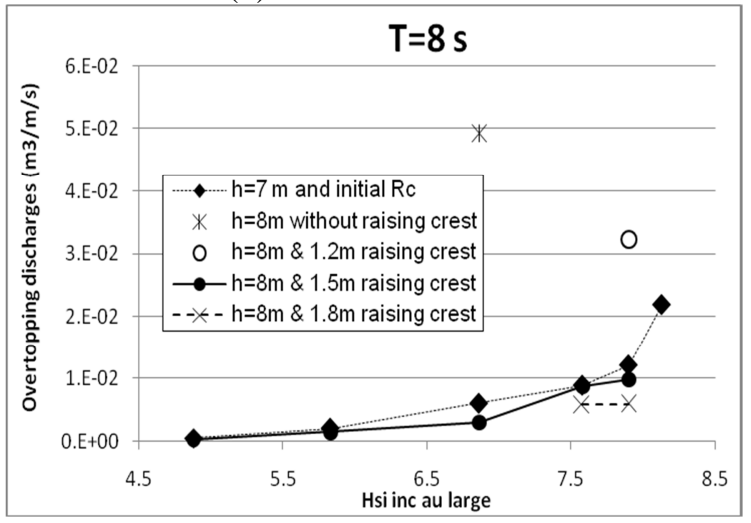

(d)

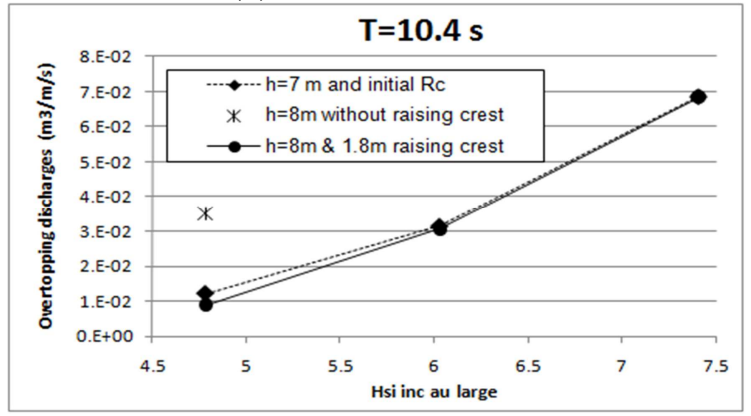

Fig. 10. Measured average overtopping rate before and after installing reinforced wall cases: (a) $T_{m}=7 \mathrm{~s}$; (b) $T_{m}=8 \mathrm{~s}$; (c) $T_{m}=9.3 \mathrm{~s}$; (d) $T_{m}=10.4 \mathrm{~s}$.

The experimental results within the ranges $7 \mathrm{~s} \leq \mathrm{T}_{\mathrm{m}} \leq 11 \mathrm{~s}$ and $5 \mathrm{~m} \leq \mathrm{H}_{\mathrm{s} 0} \leq 10 \mathrm{~m}$ show that the reinforcement of the structure have to be:

- "normal" scenario for $0.5 \mathrm{~m}$ sea level rise: $1.5 \mathrm{~m}$ crest wall rise

- extreme scenario for $1 \mathrm{~m}$ sea level rise: $1.8 \mathrm{~m}$ crest wall rise with recurved part as seen in Fig. 11

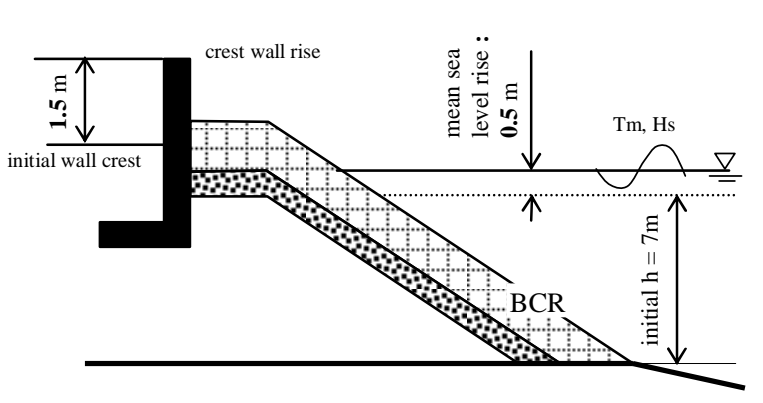

- for $0.5 \mathrm{~m}$ sea level rise: $1.5 \mathrm{~m}$ crest wall rise

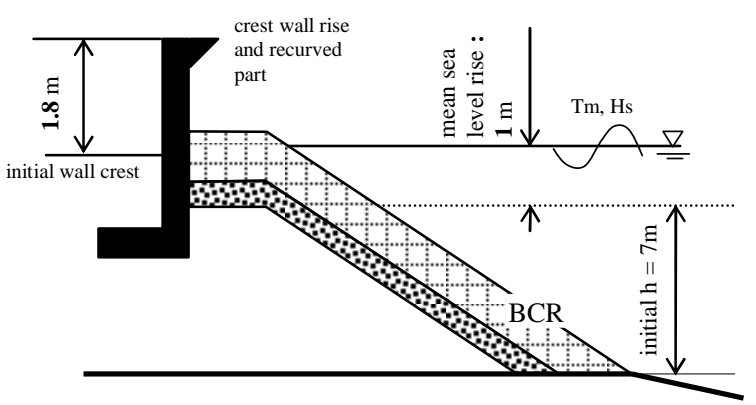

- for $1 \mathrm{~m}$ sea level rise: $1.8 \mathrm{~m}$ crest wall rise with recurved part

Fig. 11. Reinforcement results for the two scenarios of sea level rise

\section{EXTRAPOLATED FORMULA OF OVERTOPPING}

In the following, the purpose is answering the question that predicted overtopping formula can be extrapolated in case of new configuration of crest wall which has been installed. From there, the influence of existing vertical wall on top of the slope is examined by the coefficient $\gamma_{\mathrm{v}}$. This factor is accompanied in formula Owen - Besley which has a good fitness with presented test in small scale wave flume.

$$
q / g H_{s} T_{m}=C_{r} \cdot a_{0} \exp \left(-b_{0} \frac{R_{c}}{T_{m} \sqrt{g H_{s}}} \frac{1}{\gamma_{r} \gamma_{v}}\right)
$$




\section{High crown wall for raising mean sea level to $h=7.5 \mathrm{~m}$ :}

The tests with vertical crown wall have been carried out in succession additional of crest wall. The wave height and wave period are used the same in previous section with range $\mathrm{H}_{\mathrm{s}}$ from $5 \mathrm{~m}$ to $9 \mathrm{~m}$ offshore and $\mathrm{T}_{\mathrm{m}}=7 \mathrm{~s}, 8 \mathrm{~s}, 9.3 \mathrm{~s}$ and $10.4 \mathrm{~s}$ respectively. In this case, the influence of the crown wall on top of slope $\gamma_{\mathrm{v}}$ is examined.

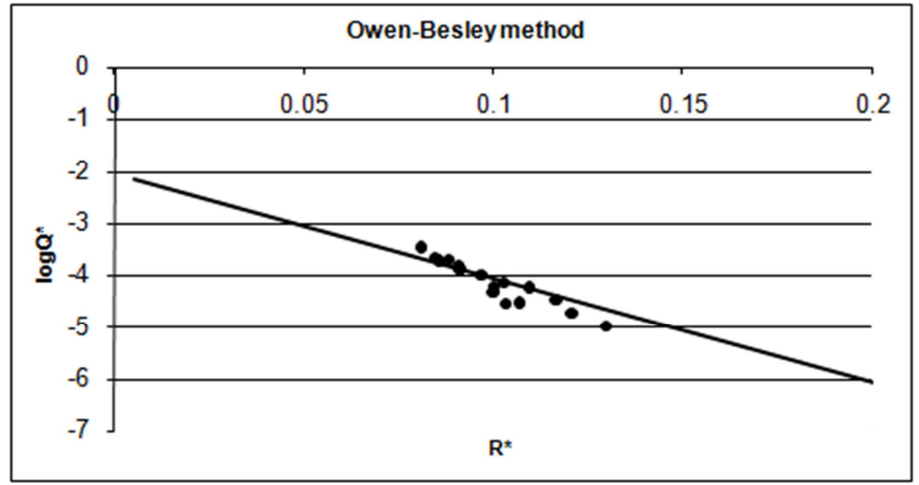

Fig. 12. Measured and predicted comparison in Owen - Besley formula with first steps of sea and crest elevations, $\boldsymbol{\gamma}_{\mathbf{r}} \boldsymbol{\gamma}_{\mathbf{v}}=\mathbf{0 . 4 2}\left(Q^{*}=\frac{q}{g H_{m 0} T_{m}}, R^{*}=\frac{R_{c}}{H_{m 0}}\left(\frac{s_{0 m}}{2 \pi}\right)^{0,5}, s_{0 m}=\frac{2 \pi H_{m 0}}{g T_{m}^{2}}\right)$.

From the graph in Fig. 12, the cluster of tests values with the predicted formula permits the authors can infer the value $\gamma_{\mathrm{r}} \gamma_{\mathrm{v}}=0.42$ in formula Owen - Besley with the least square method. In the previous section, the value $\gamma_{\mathrm{r}}=0.4$ is determined in case of without crest on top of slope. Therefore, the value $\gamma_{\mathrm{v}}$ considers the existence of additional influence crest configuration factor $\gamma_{\mathrm{v}}=1.05$. The coefficient $\gamma_{v}>1$ can be concluded that this crest configuration is less efficient than initial low wall configuration in reducing the overtopping discharge. Saying otherwise, the new reinforcement solution reduces less quantity of wave overtopping volume than existed breakwater configuration which have the same crest freeboard $R_{c}$. This is explained by the physical way that the wave is more breaking and stopping by crest berm in low wall crest than in high wall crest which has the clearance between berm and wall for waves penetrate easily without losing their energy.

\section{Recurved crown wall for raising sea height to $h=8 \mathrm{~m}$ :}

Recurved crown wall applied for extreme case of raising sea level reduces more waves overtopping as expectation than previous solution. The same manner of analysing the efficiency of this reinforcement method, the influence crest configuration is considered in figure 13:

(a)

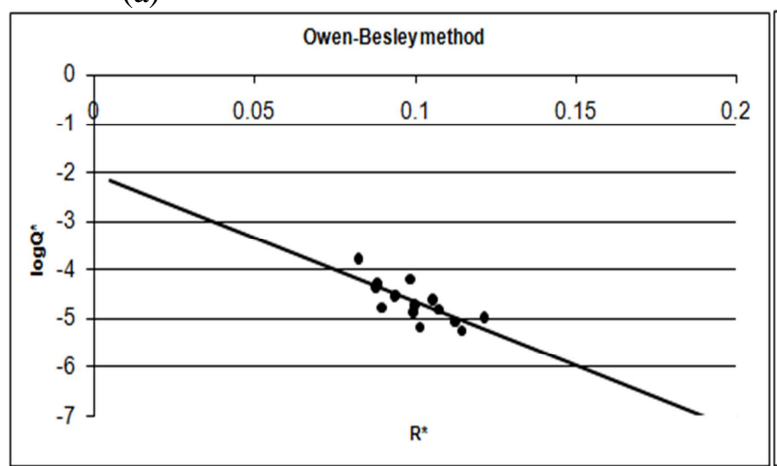

(b)

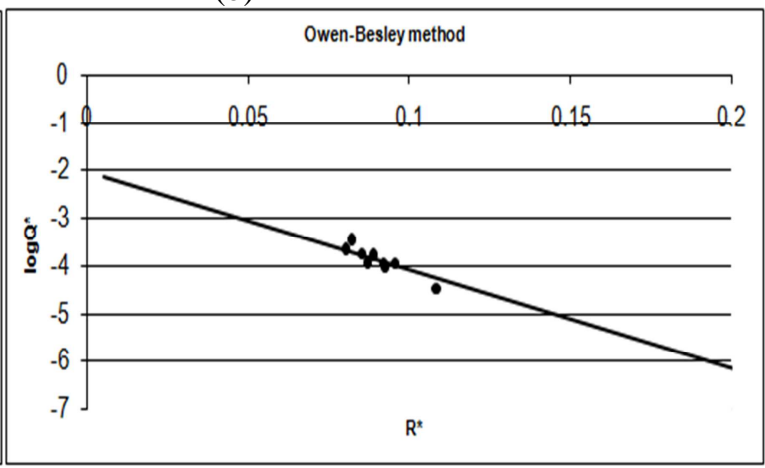

Fig. 13. Measured and predicted comparison in Owen-Besley formula with second steps of sea and crest elevations: (a) $\boldsymbol{\gamma}_{\mathbf{r}} \boldsymbol{\gamma}_{\mathbf{v}}=\mathbf{0 . 3 3}$ for $\xi_{\mathrm{m}}<3.5$ and (b) $\boldsymbol{\gamma}_{\mathbf{r}} \boldsymbol{\gamma}_{\mathbf{v}}=0.42$ for $\xi_{\mathrm{m}} \geq 3.5\left(Q^{*}=\frac{q}{\sqrt{g H_{m 0} T_{m}}}, R^{*}=\frac{R_{c}}{H_{m 0}}\left(\frac{s_{0 m}}{2 \pi}\right)^{0.5}\right)$. 
About recurved wall configuration, the $\gamma_{\mathrm{v}}$ evaluation is separated in two ranges of $\xi_{\mathrm{m}}$. The values $\xi_{\mathrm{m}}>3.5$ corresponds to surging waves with periods $\mathrm{T}_{\mathrm{m}}=9.4 \mathrm{~s}$ and $10.3 \mathrm{~s}$ and the values $\xi_{\mathrm{m}}<3.5$ corresponds to plunging waves with periods $T_{m}=7 \mathrm{~s}$ and $8 \mathrm{~s}$. As result, the value of $\gamma_{\mathrm{v}}=1.05$ can be applied for surging wave. Especially, for shorter incident waves the value of $\gamma_{v}=0.83(<1)$ proves that due to its recurved part, this reinforcement configuration decreases the overtopping more efficiently than the breakwater with higher armour's crest $\mathrm{A}_{\mathrm{c}}$.

For this reason, in the closed sea having permanent shorter incident waves, the recurved crown wall need to be considered to apply in design because of its low cost and convenience for construction. Table 4 presents the guide of using factor $\gamma_{v}$ in design with various types of crest walls.

Table 4. Summary for influence crest configuration factor $\gamma_{v}$.

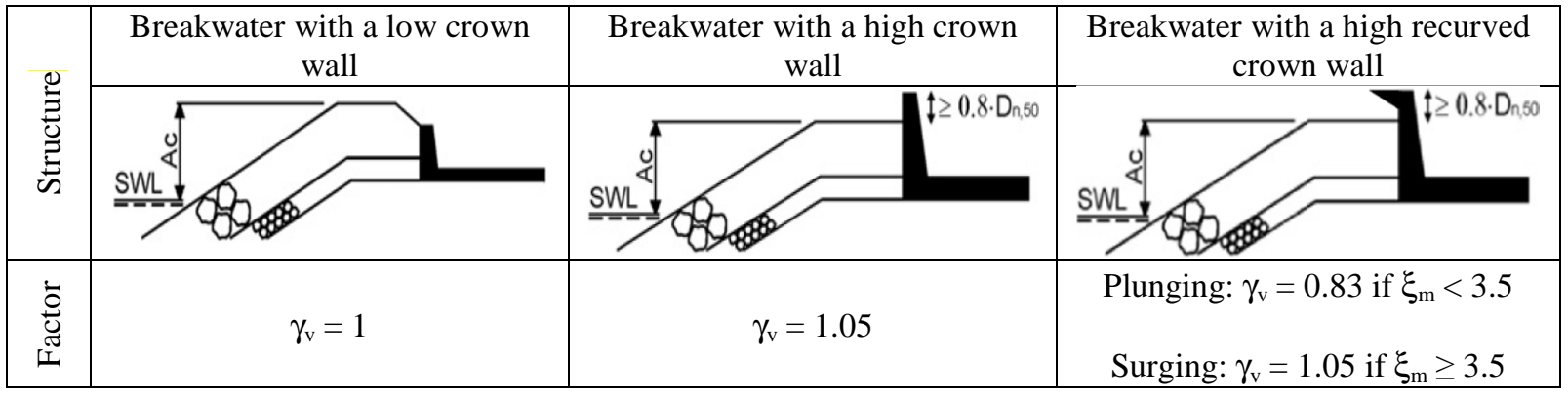

\section{CONCLUSIONS}

The average overtopping rates in these tests have been compared with predicted values from the widely used prediction formulae from Owen (1980) and Van der Meer (1998) with reduction factor Besley (1999). Applying a correction factor $\gamma_{s}$, it's successful to obtain reliable field data in comparison with presented test model just in case of Owen formula. For application of these formulae to in situ Antifer breakwater, the value of reduction factor for the surface roughness of armoured layer used is $\gamma_{\mathrm{r}}=$ 0.49. Van der Meer formula, however, will give more evidently overtopping discharge than tests in small scale model which leaves for further discussion with another model test with the same condition of offshore incident wave and type of work.

So far, both vertical and recurved crown wall have been used in the reinforced solutions, with normal and high rising of sea level due to climate changing, to conserve initial wave overtopping discharge in storm duration of 3 hours. In general, it can be concluded that the recurved crown wall has a better resistance than vertical one in withstanding the wave overtopping, moreover, the recurved wall sustains more efficiently in short wave overtopping than in long wave overtopping.

Finally, former researches of many authors about the effects of various type of breakwater's crest in overtopped wave have been introduced. In this paper, authors present a factor $\gamma_{\mathrm{v}}$ which expresses the influence of crest configuration on overtopping rates. To have more reliable estimation of crest effects, it is preferable in the future to continue carrying out more tests with various solutions of crest type.

\section{ACKNOWLEDGEMENTS}

In this report, small scale $\mathrm{E}=30.5$ test carried out at the LOMC Le Havre in year 2011 have been presented. As a partner in research project of SAO POLO, the study was partly financed by CETMEF and the contribution of Antifer blocks from EDF R\&D is acknowledged.

\section{REFERENCES}

Besley P., 1999. Wave overtopping of Seawalls. Design and Assessment Manual. Hydraulics research Wallingford. R\&D Technical Report W178, ISBN 185705069 X.

Briganti, R., Bellotti, G., Franco, L., De Rouck, J., Geeraerts, J., 2005. Field measurements of wave overtopping at the rubble mound breakwater of Rome-Ostia yatch harbour, Coastal Engineeing 52, pp. 1155-1174.

Bruce, T., Van der Meer, J.W., L. Franco, Pearson, J.M., 2008. Overtopping performance of different armour units for rubble mound breakwaters, Coastal Engineering Volume 56, Issue 2, February 2009, pp. 166-179. 
CIRIA, CUR, CETMEF, 2009. Guide enrochement. L'utilisation des enrochements pour les ouvrages hydrauliques. Version français du Rock Manual, CETMEF, Compiègne.

EurOtop, 2007. Wave Overtopping of sea defences and related structures - Assessment manual. Archive for Research and Technology on the North Sea and Baltic Coast.

Frens, A. B., 2007. The impact of placement method Antifer-block stability. MSc-thesis, Delf University of Technology.

Geeraerts, J., Troch, P., De Rouck, J., Willems, M., Franco, L., Bellotti, G., Briganti, R., 2004. Wave overtopping at Ostia yacht harbour breakwater: comparison between prototype and model tests in 2D and 3D. Proc. 29th ICCE, Lisbon, Portugal, 19-24 September 2004. pp. 4288-4300.

Lykke Andersen, T., Burcharth, H.F., Gironella, X., 2011. Comparison of new large and small scale overtopping tests for rubble mound breakwaters, Coastal Engineering 58, pp. 351-373.

Owen, M.W., 1980. Design of seawalls allowing for wave overtopping. Hydraulics Research, Wallingford, Report No. EX 924, UK.

TAW, 2004. Dutch Technical Advisory Committee on Flood Defence. Technical Report on Wave run-up and Wave overtopping at dikes. Delft, the Netherlands.

Troch, P., Geeraerts, J., Van de Walle, B., De Rouck, J., Van Damme, L., Allsop, W., Franco, L., 2004. Full-scale wave overtopping measurements on the Zeebrugge rubble mound breakwater, Coastal Engineering 51, pp. 609-628.

Van der Meer, J. W., 1998. Wave Run-Up and Overtopping, Chapter 8 in: "Seawalls, dikes and revetments". 